\title{
Augmented Reality and MS-Kinect in the Learning of Basic Mathematics: KARMLS Case
}

\author{
Raúl Lozada-Yánez ${ }^{1,2}$, Nora La-Serna-Palomino ${ }^{1} \&$ Fernando Molina-Granja $^{3}$ \\ ${ }^{1}$ Universidad Nacional Mayor de San Marcos, Faculty of Systems and Information Engineering, Ecuador \\ ${ }^{2}$ Escuela Superior Politécnica de Chimborazo, Faculty of Informatics and Electronics, Riobamba, Ecuador \\ ${ }^{3}$ Universidad Nacional de Chimborazo, Faculty of Engineering, Riobamba, Ecuador \\ Correspondence: Fernando Molina-Granja, Universidad Nacional de Chimborazo, Faculty of Engineering, \\ Riobamba, Ecuador.
}

Received: May 8, 2019

doi:10.5539/ies.v12n9p54
Accepted: June 19, $2019 \quad$ Online Published: August 29, 2019

URL: https://doi.org/10.5539/ies.v12n9p54

\begin{abstract}
By its nature, the learning of certain complex contents has always been a focus of attention and a challenge in the study of mathematics. This fact acquires greater importance if it is about the learning of children, because the psycho-cognitive skills of this type of user, especially when they attend the first levels of Basic General Education are not yet mature. As a result, children are unable to assimilate correctly and easily certain content of an abstract nature during the early stages of mathematics learning. This study presents the results of the application of a computer system called "Kinect based Augmented Reality Math Learning System - KARMLS", whose design and development uses the Augmented Reality technology and the motion sensor implemented in MS-Kinect camera. The developed application covers elementary math topics corresponding to the Basic General Education curriculum of the Republic of Ecuador. The study used an experimental quantitative approach, involving 29 third-grade children (13 girls and 16 boys), who attend to 2 Basic General Education schools in Riobamba city, Ecuador. The results that allowed to evaluate the prototype proposed in the study were obtained by means of a pretest and a posttest, which were contrasted with the students' t-test for paired samples. Through the analysis of data obtained and the discussion, it is concluded that the applied computer system had a positive effect for the learning when used as a supplementary tool in the classroom and that it was more effective in children who previously had low performance than with those of high performance. Also, the children were motivated and with positive attitudes regarding the use of the analyzed software.
\end{abstract}

Keywords: basic education, ms-kinect, human computer interaction, mathematics

\section{Introduction}

Mathematical experiences are intrinsic to our daily life, however, the understanding of abstract contents has always been a topic of interest and a challenge in the learning of this subject at all levels of academic formation, this situation becomes more relevant if it deals with children of school age since, the abstractions that they must carry out in order to make certain contents theirs are complicated tasks that hinder their comprehension. This issue is also important when educating with didactic digital resources, since most educational software developers do not consider the particular design requirements that this type of users need due to the changes that, due to their age, occur in his psycho-cognitive abilities (Gossen, Nitsche, \& Nürnberger, 2013; Lozada, Rivera, \& Molina, 2018). As a result of the above, children are not able to assimilate certain contents correctly and easily during the first stages of mathematics learning.

Videogames companies develop input computing devices based on motion sensors. This type of devices allows users to operate and interact with videogames through their gestures and body movements, whether these movements of their hands, arms, legs or other parts of their body, this makes the interaction of these users with the software be done more naturally. The devices of this type that are more frequently used are Wii from Nintendo (Lee, 2008), MS-Kinect from Microsoft, and Sony's PS Move. Additionally, it is urgent to carry out training courses for professors on the applied behavior analysis strategies and their applications (Khaleel, 2019).

This type of technology, as well as the possibility of having at hand a database of historical information on the application of this type of technology for future considerations and research (Molina-Granja \& Rodríguez-Rafael, 
2017b), has aroused the interest of many researchers and developers who study the possible uses of said technology with a computer. Currently, there are software tools that make it possible to use this type of device with desktop applications. In this context, several works have been developed that study the applications of these devices in various areas of human endeavor.

Co-teaching enables a large range of teaching practices to be employed including a partnership between the student-teacher and the teacher in all the processes that occur in the classroom, share the planning of time and tasks, planning feedback conversations, reflective thinking and evaluation of the teaching. Thus, the contribution of co-teaching is significant for all those involved, enabling the use of a wide range of teaching practices, something that without co-teaching would be difficult to perform. (Neifeald \& Nissim, 2019).

The use of motion sensors as alternatives to common peripherals (keyboard and mouse) and their combination with Augmented Reality (AR) technology, is presented as a new option for the teaching-learning of subjects that, like mathematics, have been seen limited mainly to the presentation of their contents (intrinsically abstract and complex) through static didactic resources printed in textbooks, these resources require the use of a high extrinsic cognitive load (Sweller, 2010; Sweller, Van Merrienboer, \& Pass, 1998) from the students, besides being boring for the users, more if it is about children. The proposal presented in this paper aims to improve the usability of traditional didactic digital resources (usually slides), by reducing the cognitive load necessary to learn certain curricular contents corresponding to the elementary mathematics subject through the use of the natural user interface proposed by the computer system called "Kinect based Augmented Reality Math Learning System", hereinafter referred to as KARMLS.

When a student has access to educational content presented by a computer, he is forced to use the type of interaction with the computer equipment (usually provided with a keyboard and a mouse), without forgetting that he must also become familiar with interactions such as the management of windows, access to menus, use of console commands, use of specific interfaces of each computer application, and others that may vary depending on the operating system and the software used. Therefore, while students learn how to perform all these interactions, there is an extra cost of learning that uses user memory in these tasks whose learning is not the main objective of the digital resources used (Sweller, 2010), this strange load is known as extrinsic cognitive load.

One of the most known and important cognitive characteristics of the human being is its limited processing capacity Sweller (1994), who also points out that the didactic resources with which a student interacts must be designed taking into consideration the characteristics of the extrinsic cognitive load that these resources generate in their target audience, this evidence suggests that the interactivity between the human being and the elements (digital or not) with which the information that is desired is assimilated by a student, can be an important aspect in the process of designing teaching resources. In this sense, it is necessary to reduce the extrinsic cognitive load, that is to say "the unnecessary cognitive load that saturates, contaminates and affects the working memory (Lotero, 2012)" to increase the relevant load space in the working memory (Chong, 2005; Shaffer, Doube, \& Touvinen, 2003).

In an effort to achieve the above, this paper presents KARMLS, a learning system whose main strategy is to minimize the extrinsic cognitive load generated by the use of digital teaching resources based on traditional interactions (Keyboard and mouse), through the incorporation of a gestural interface (using the movement sensor of MS-Kinect) that takes advantage of the cognitive abilities of the children participating in the study, as well as the knowledge that they have acquired throughout their lives when interacting with the physical world (Lozada et al., 2018 ), KARMLS combines this interaction mode with Augmented Reality (AR) technology, which allows digital objects to be incorporated into a real environment, where that can interact and be manipulated by the user, covering certain contents of elementary mathematics, aimed at children who attend primary school, also examining their effect on the cognitive performance of students, comparing their effects on high-performance students and low performance and investigating the attitudes of children towards software.

\section{Literature Review}

Although mathematics is the language of the universe (Khan, Trujano, Choudhury, \& Maes, 2018), human beings commonly experience a "mathematical anxiety" largely attributable to the traditional form (presenting static and boring content in textbooks) in that this subject is taught and by the use of abstract symbols that in principle have no meaning for students, as a set of rules that must be memorized instead of understood and in a vertical education system, facts that, in certain cases, convert the learning mathematics in a punishment, this generates a lack of interest in learning this important subject, disinterest that according to Ellis, Fosdick, \& Rasmussen (2016), leads to a high dropout rate in the fields of science, technology, engineering, and mathematics.

In Perkins (1999), a discussion about constructivist learning was performed; results of this study indicate that a 
great part of the students obtains their knowledge through observation. Seymour Papert started from the bases of constructivist learning to propose his theory of constructionist learning, in this approach, students build their own knowledge while designing, building and executing projects. Its language of programming of logos (Papert, 1999), based on its approach, allowed the learning of the geometry of constructionist forms.

Computer simulations are popular in the educational field, mainly in the subjects in which contents are presented that are difficult to understand due to the lack of visualization of said contents in real life, in this sense and thinking that the target audience of this study are children of school age, the presentation of a learning system that is shown as a computer game can improve the learning of mathematics (Cordova \& Lepper, 1996), even more if this fact is added the benefits that according to Lozada et al. (2018), has the development of didactic digital resources developed with AR and a gestural interface, and the foundations of the constructivist approach, KARMLS is presented as a learning system that allows children of Basic General Education to learn in a playful way within an environment that combines virtual elements with a real-world vision (AR).

Many developments have presented applications based on AR for learning with real environments, in Bujak, Radu, Catrambone, Macintyre, Zheng, and Golubski (2013) analyze several factors that may affect the educational effectiveness of AR-based interventions for mathematics classrooms and offer theoretical foundations to understand the benefits and limitations of AR-based learning experiences, these researchers present a framework of work to understand the learning of the AR from three perspectives: a) physical "physical manipulation allows natural interactions, thus promoting the creation of embodied representations for educational concepts", b) cognitive "space-time alignment of information through experiences of AR can help the student's symbolic understanding by scaffolding the progress of learning " and, c) contextual "AR technology creates possibilities for collaborative learning around virtual content and non-traditional environments, which ultimately facilitates personally significant experiences". Results of this work indicate that, although AR technology shows great potential to expand the resources used to educate, there is still research to be done.

Another interesting case is Construct3D (Kaufmann, 2002), work that presents a prototype based on Augmented Reality for Mathematics and Geometry that can be used collaboratively or not, to improve spatial skills and experimentation through geometric constructions for secondary and university level, this implementation employs a stereoscopic screen on the user's head (Head Mounted Display, HMD) and a Personal Interaction Panel (PIP) to simplify user interaction with the 3D models presented. The implementation of this prototype, according to its developers, allowed to demonstrate that even though its prototype has some similarity with Computer Assisted Design (CAD) software, in turn, it is presented as a simple construction tool that allows to comprehensively cover the needs of basic Geometry educators, who do not need the wide variety of specific and complex features of CAD software, which are very powerful tools, but with a long and gradual learning curve that generates high extrinsic cognitive load while learning to use them, a fact that is overcome with the use of Construct3D.

\subsection{MS-Kinect and Its Applications}

MS-Kinect from Microsoft, is an electronic device that allows the capture of the movement of the complete body of an user and the recognition of their gestures through the RGB camera and infrared depth sensors that it incorporates MS-Kinect allows users to control a console or a PC application without any device that limits their movements, unbinding in this mode the user and the hardware. As seen in Figure 1, the sensors incorporated in this device allow MS-Kinect V2 (or PC version) to recognize 25 anatomical landmarks of a subject.

In general, up to six users can be recognized by this device (Kitsunezaki, Adachi, Masuda, \& Mizusawa, 2013). The first version of the device generated a cloud of color points and detected 20 anatomical landmarks, as shown in Figure 2, recognizing a maximum of two subjects (Khoshelham \& Elberink, 2012). The RGB camera of the device

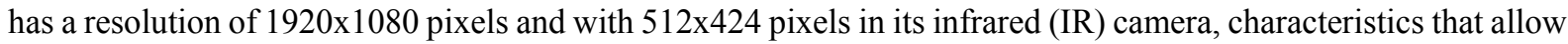
MS-Kinect to capture images in a field of 70 degrees horizontally and 60 degrees vertically, with a maximum frequency of $30 \mathrm{~Hz}$ (Kitsunezaki et al., 2013). 


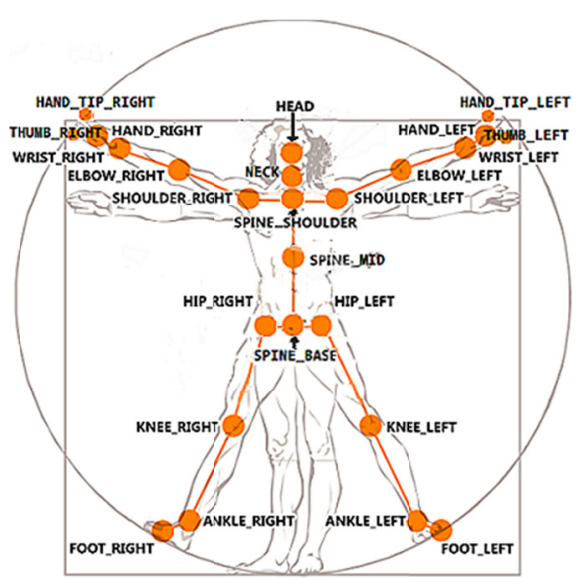

Figure 1. Benchmarks recognized by MS-Kinect V2

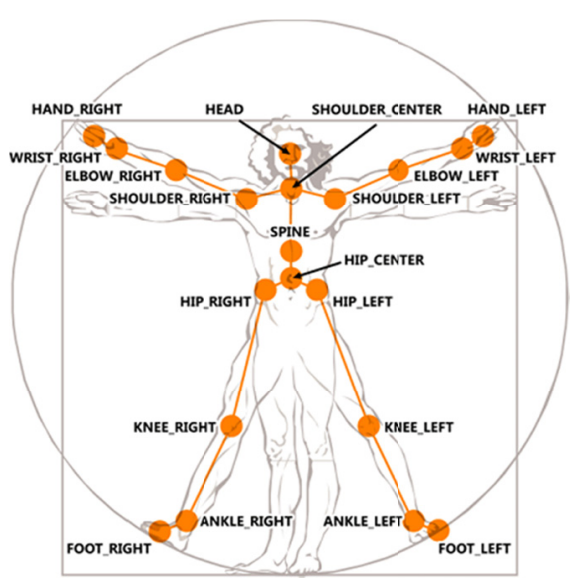

Figure 2. Benchmarks recognized by MS-Kinect V1

Since its launch, MS-Kinect has been employed in several branches of human endeavor, below are some of the areas and applications in which this device has been used successfully:

\subsection{Robotics}

The MS-Kinect sensor is used in this area for the improvement of the artificial "vision" of the robots. Romero-Molano and Díaz-Celis (2001) and Stowers, Hayes, and Bainbridge-Smith (2011) present some examples of the application of this sensor as a source of information about the environment, information that is used to procure the autonomous navigation of robots.

\subsection{S Scanning}

Among the data provided by the MS-Kinect sensor, depth information is included, this type of data can be used in the 3D scanning of objects and scenes, examples of this type of application can be seen in Cui and Stricker (2011) and in Izadi et al. (2011).

\subsection{Human-Computer Interface}

Recent works seek to bring the type of interaction without controls provided by MS-Kinect to areas different from that of videogames since it has been shown that it can be constituted in a more "natural" way with which users can interact with computer applications. In Gallo, Placitelli, and Ciampi (2011) an example of this type of study is presented, in it, a system of medical images is implemented, and in Boulos et al. (2011), an interface that allows interaction with Google Earth based on gestures.

\subsection{Medicine}

In the field of medicine, the use of information of the whole body that is obtained without the use of additional controls is convenient for therapeutic systems and rehabilitation of patients with mobility problems. As examples of this type of systems are observed in Bravo et al. (2011), in this work, a configurable platform for physical exercises is presented; Huang (2011) presents a rehabilitation system for patients suffering from muscular atrophy and cerebral palsy.

\subsection{Education}

Shortly after the appearance of MS-Kinect, research was published that indicated that this type of device could be useful in the educational field. As an example of this, in Johnson, Adams, and Cummins (2012), the emphasis is placed on the potential of the devices that enable natural interaction (among which is MS-Kinect), especially in K-12 education (primary and secondary education in the United States) and assistance to people with special needs. In DePriest and Barilovits (2011), it is also described how the combination of Xbox Live and MS-Kinect can be used in education. In the same way, Kandroudi and Bratitsis (2012) discusses how some commercial games can be used for educational purposes. Additionally, preservation techniques must be considered in order to have a history and project improvements in educational processes in the long term (Molina-Granja \& Rodríguez-Rafael, 2017a).

Among the various existing analyzes on MS-Kinect as a tool in education, we can highlight the research carried out in Hsu (2011), in which the potential benefits of this device in the classroom were studied. Despite not testing any 
type of system and/or prototype, this study concluded that the possible benefits of this type of technology are promising and that its use could help in the improvement of teaching, points out that its success or failure in the use of this device for educational purposes will depend to a large extent on the availability of applications that can be used with the device.

According to Hsu (2011), the benefits of using MS-Kinect are those mentioned below:

- Teachers can interact with the contents displayed on the screen through gestures, movements, and voice instead of the keyboard and the mouse.

- The teacher can share the control of the screen with the students, thanks to MS-Kinect allowing interaction with more than one user. This may allow activities such as group work or one-on-one interaction between teacher and student.

- MS-Kinect can serve as a support for the teaching of physical activities, such as dance or martial arts.

- MS-Kinect can encourage the participation of students in the class. Since this sensor is a stimulating tool, interesting applications can be created to capture the attention of students.

In this work, the authors also present the possible inconveniences that could arise with the use of this interaction device in the classroom, so it is mentioned that:

- MS-Kinect requires an empty space between the user and the device (at least $0.8 \mathrm{~m}$ ), in addition to the space that the user needs to move and interact with the screen. This amount of space may not be available in the classroom.

- There are not many applications with MS-Kinect available that can be used by teachers in class, so teachers do not have many alternatives if they want to bring the MS-Kinect sensor to their classes.

As already mentioned, MS-Kinect allows human-computer interaction through the movements and gestures of the extremities (for example) of the human being, this type of interaction may be appropriate for the development of hand-eye coordination in children of preschool. As mentioned in Ortega \& Obispo (2007), it is a kind of coordination, also called manual coordination; it is defined as "the ability of an individual to simultaneously use their hands and eyes in order to perform a task or activity". The development of this skill is important for infants since it will depend on the ease with which they acquire reading and writing skills.

The system developed by this study consists of three games aimed at children who attend two Basic Education Units in Riobamba, Ecuador. The tool called KARMLS, uses MS-Kinect as the system's input device, this device allows children to interact with the didactic objects presented by movements that they make with their hands, in this way they exercise the manual vision (hand-eye) coordination. The tool was tested through a field test, which is, in a classroom suitable for that purpose, making the children try individually, but working in pairs with two roles, being at one time an observer of the activities of their partner and in another moment who interacts with the KARMLS tool.

The mobile devices' proliferation and their massive use by children of all ages raise new issues from the families and educators in the world, there are a new lot of questions born in this sense with regard to their quality, appropriateness, and adaptation for these users. As mentioned in Lozada et al. (2018), many of these problems occur because most software is developed for a target audience different from that of children, so the techniques and methodologies for software design (educational or not), do not consider the special characteristics and specific that children present in each of the stages of their motor, cognitive, emotional and affective development. This study aims to verify the effect of the use of a computer application based on the potential of the Augmented Reality technology and the natural user interaction provided by MS-Kinect, in the performance of a group of children of the third grade of EGB, the city of Riobamba, Ecuador. It is expected that the motivation (emotional and affective stimulation) provided by the Augmented Reality and the new way of interaction (motor, cognitive stimulation) provided by MS-Kinect will improve the qualifications obtained by the children participating in the study after KARMLS use.

\section{Methodology}

The appropriate choice of a study design makes it possible to connect the conceptual stages of the research process, such as the problem statement, the development of the theoretical perspective, and the hypothesis with the subsequent phases, in which character is more operative (Sampieri, Fernández, \& Baptista, 2014). In this sense, this study used a prospective, longitudinal, analytic and experimental quantitative approach with intervention, involving 29 third-grade children (13 girls and 16 boys), who attend to 2 Basic General Education schools in Riobamba city, Ecuador, the study aim is to evaluate the proposed prototype by means of a pretest and a posttest, 
which were contrasted with the students' t-test for paired samples. To establish the sample, a non-probabilistic discretionary sampling was used because it was necessary to seek the consent of the educational units that would participate so that the children who attend there can be part of the study.

\subsection{The Experiment, Justification, and Preparation}

The main objective of the study is to analyze the effect of digital didactic resources based on Augmented Reality as supplementary material in a basic mathematics course, specifically for content learning: a) "Sort" or "Ordenar", an activity that tries to order a certain number of elements from the largest to the smallest or vice-versa, b) "Match"or "Parear", where the student must associate several sets with the number of elements that each set contains and c) "Add" or "Sumar", an activity in which two cardinal numbers must be added to get the answer shown. Before the development of the KARMLS tool, an interview was held with the mathematics teachers, who based on their teaching experience, knew that their students were not very motivated and did not fully understand the contents presented in these specific topics. After that interview, the teachers expressed interest in reviewing these contents again with the help of a tool that uses AR technology to awaken and stimulate the interest of their students and improve the learning of the contents.

The pretest data will be provided by the teachers based on the learning results obtained by their students when traditional classroom resources were used (textbook and static slides). On the other hand, the posttest scores were obtained from the learning results of the same group of students after the use of KARMLS, which was used as support for teaching the contents specified above. It should be mentioned that none of the resources presented to the students contained the exact items of the evaluation that was made after the use of the proposed prototype, this implies that to select their answers, each student had to reach their own conclusions from the exploration, the exercise and the deduction, fundamentals of learning by inquiry, posture in which the design of the class was based. To fulfill the objectives of the study, it was necessary to adapt a classroom to assemble the infrastructure that allows properly using the KARMLS tool. The experiment design considered the execution of 4 phases, as shown in Table 1.

Table 1. Executed experimental design

\begin{tabular}{ll}
\hline Experiment Phase & Methods \\
\hline Pretest & Before KARMLS use, each student individually had to complete a written test that measured their learning outcomes \\
& with respect to the topics "Ordenar", "Parear" and "Sumar". \\
& The study participant children were instructed again in the classroom by their teacher in the subjects on which they \\
& would practice with the KARMLS tool. After this, without performing the exercise proposed in the textbook of the \\
& subject, were gathered in a random manner in 13 groups of 2 children (and a group of three children) to form work
\end{tabular}

Made by the authors.

\subsection{Used Instruments}

In research, for many experimental designs, the pretest-posttest design is the preferred method to compare participant's groups and measure the degree of change occurring as a result of treatments or interventions. For this study case, the researchers select this experimental design because they want to monitor the effect of KARMLS system (which includes AR Technology and the natural user interaction provided by MS-Kinect) upon a group of children in scholar age. For the tests' validation, the adopted criteria were the experts' analysis, in this form, 5 expert teachers in mathematics with a university degree reviewed the pretest and posttest items, this phase aimed to 
evaluate the clarity and relevance of each of the 32 items included in the pretest and the posttest. For the phase of item analysis and consistency analysis, an adjusted pilot test was applied based on the adjustments of the expert judges. This pilot test was applied to 30 students who were in the 5th grade of Basic General Education, 12 girls and 18 boys. The tests' items validation was carried out through the following phases:

a) Construction phase: Despite initiating the research with a test already constructed and reviewed by a group of teachers in the area of mathematics of one of the participating schools, the process was carried out of validation by judges and item analysis.

b) Judges' validation: The 32 original items in the test were organized in a validation booklet, in order to determine the relevance and clarity of the items by means of the Reason of Content Validity (CVR) of each one of the items.

c) Initial adjustments: Based on the level of agreement of the judges and their recommendations, the items with non-permissible values of CVR, were modified according to the criteria of Lawshe (1975), (cited by Cohen, 2001).

d) Pilot test: As already mentioned, the test was applied to 30 students of fifth grade EGB previously divided into 2 groups corresponding to the two parallels of the level, the application conditions were equalized in times (80 minutes) and spaces (classroom).

e) Reliability analysis: with the obtained data in the pilot test and since it was not possible to carry out a method of double application, it was decided to perform an analysis of internal consistency implementing the method of split-half.

The results of these tests corroborated the clarity and relevance of each of the 32 items included in the pretest and the posttest.

Before the execution of the experiment, the teachers applied the previous test (pretest) with the whole class; After this, the researchers divided the class randomly into 13 groups of 2 and a group of 3 students who, as already mentioned, used the tool proposed in this study to complete the proposed learning tasks for the "Ordenar", "Parear" and "Sumar" topics, under the research team supervision. After learning with KARMLS, a subsequent test (posttest) was carried out, using a test with the same complexity and evaluating the same contents as in the pretest. The main objective of these tests was to examine the understanding and abstraction of knowledge that allows them to perform the tasks exercised with the use of the AR-based tool proposed by this study.

\subsection{Development of the Prototype}

KARMLS system is an Augmented Reality software with support for MS-Kinect, which makes the use of AR markers as a method of interaction dispensable. The software developed contains three specific learning activities: "Ordenar", "Parear" and "Sumar" and an introductory activity aimed at indicating to the participating children the way in which MS-Kinect allows them to interact with the software. Children's Gestures were used as a way of human-computer interaction, in this sense, according to each activity the child can interact with virtual objects by the movement of their hands.

\section{1) Design considerations}

A constructivist design model centered on the student and a learning approach based on inquiry was used, under which the children were gathered in 13 pairs and a trio to form groups of work, they built their own knowledge, they used gestures of their hands to manipulate the virtual objects of each activity proposed in KARMLS, this interaction was carried out as if they were doing it with objects from the real world, thus taking advantage of their previous knowledge and diminishing the extrinsic cognitive load through the use of augmented reality (Wei, Guo, \& Weng, 2018), a fact that is further improved by using the natural user interface provided by MS-Kinect instead of the traditional devices used by desktop computers, this devices disappear from the user's view with the use of the interaction proposed by KARMLS. When considering the prototype's design, it was decided to implement the KARMLS games with simple functionalities that contemplate the topics of the area of mathematics reported as not fully assimilated by the children. After analyzing the aforementioned information, it was decided to implement the following educational activities:

- "Sumar". In this activity the child can visualize the sum components, being able to alter the result if he adds or eliminates elements of the addends, by means of a drag and drop action supported by the motion sensor.

- "Ordenar". In this activity, the child arranges objects of different sizes with the criterion of minor to major or vice versa by dragging them and placing them in the corresponding box.

- "Parear". In this activity, the child must associate several sets of elements with their numerical representation 
by drawing a line with the gesture point.

In this phase, it has also been considered that the prototype should have some flexibility in terms of its content so that the teacher can adapt the prototype according to their criteria, options that will be seen later.

2) Development tools

For the development of the proposed prototype, it was considered to use libfreenect (http://openkinect .org), OpenNI (https://github.com/OpenNI/OpenNI) and the official MS-Kinect SDK for Windows (https://www.microsoft.com/en-us/download). The Libfreenect software allows receiving raw data from MS-Kinect. The open source SDK OpenNI allows the development of applications with natural interfaces. In the case of this study, OpenNI allows the recognition of children hands. The MS-Kinect SDK for Windows is a complete framework that offers everything from raw information process (audio, RGB images, and depth images) to advanced information processes such as the simultaneous tracking of the skeleton of up to 6 users, face tracking and recognition.

For the selection of the appropriate development tools of the prototype, several criteria were considered. Table 2 shows a summary, where the options considered as favorable are those that have been highlighted with an asterisk. Figure 3 shows an illustration of the stack of technologies used.

Table 2. Comparison of features of the tools available for development with MS-Kinect

\begin{tabular}{|c|c|c|c|}
\hline & Libfreenect & $\begin{array}{l}\text { SDK for } \\
\text { MS-Kinect }\end{array}$ & OpenNI \\
\hline License & * Apache v2/GPL v2 & Private & * Apache v2 \\
\hline Operating system & * Linux, OSX, Windows & Windows 7,8 & $\begin{array}{c}\text { * Windows, OSX 10.6+, Ubuntu 12.04+, } \\
\text { Linux Mint } 12+\end{array}$ \\
\hline $\begin{array}{l}\text { Programming } \\
\text { languages }\end{array}$ & $\begin{array}{c}* \mathrm{C} \text {, with wrappers for Java, C++, C\#, Python, } \\
\text { Javascript. }\end{array}$ & $\mathrm{C}++$ & $\mathrm{C}$, whit wrappers for $\mathrm{C}++\mathrm{y}$ Java \\
\hline Recording & Yes & * yes & $*$ yes \\
\hline Skeleton Tracking & No & * yes & * yes \\
\hline Gesture recognition & No & * Create gestures & * Predefined gestures \\
\hline Calibration & No & $*$ yes & $*$ yes \\
\hline
\end{tabular}

Made by the authors.

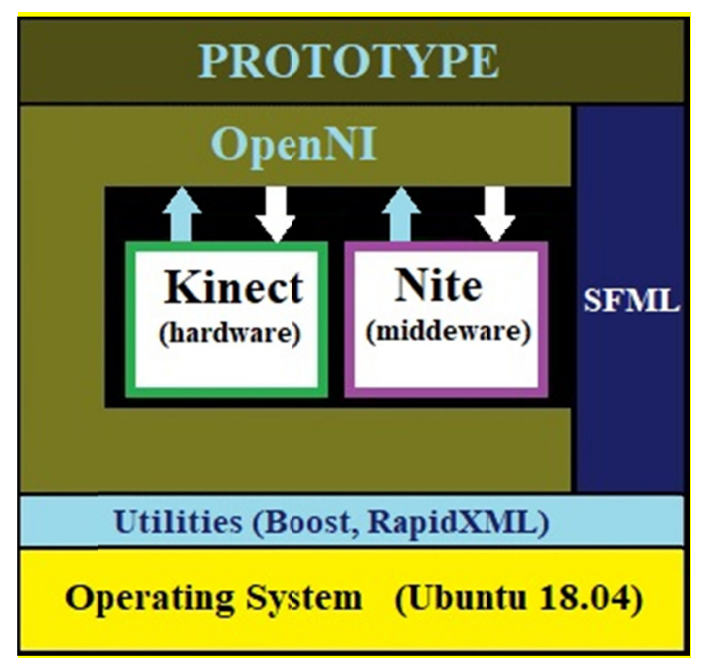

Figure 3. Technologies used in the development of the prototype

3) Human-computer interaction

The mentioned tools do not impose the form of interaction between the user and KARMLS, for this reason, the interaction mode should be designed in a way that is suitable for the study scenario. As seen in Figure 4, in many computer applications based on gesture interaction, the user can interact with the application with the use of their 
hands as a "pointer", that is reflected on the display device used. Just as in a desktop environment, in which the user can use the mouse to move the pointer across the screen and use a click or double click to indicate an action, in an environment based on gesture interaction, the user uses his hand to point and make gestures to indicate actions. The gestures can be done either with your hands or even with the rest of your body, for the case of this study, the gestures can be done with both hands (one at a time).

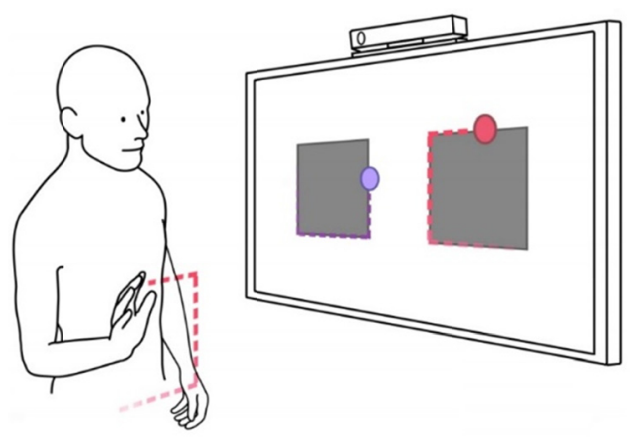

Figure 4. PathSync's interaction metaphor (Carter, Velloso, Downs, Sellen, O’Hara, \& Vetere, 2016)

OpenNI supports certain predefined gestures that were used for the prototype. To initiate the interaction with the system, the user is required to make a "wave" gesture and for the activation of the buttons and the selection of elements, the "click" gesture is used. The "click" gesture is performed by extending the open hand, towards the MS-Kinect sensor and then moving the hand back towards the body. The movement must travel a distance of at least $20 \mathrm{~cm}$. The "wave" gesture is executed by moving the hand horizontally several times. Figure 5 shows several children interacting with software whose interaction is based on the motion sensor MS-Kinect.

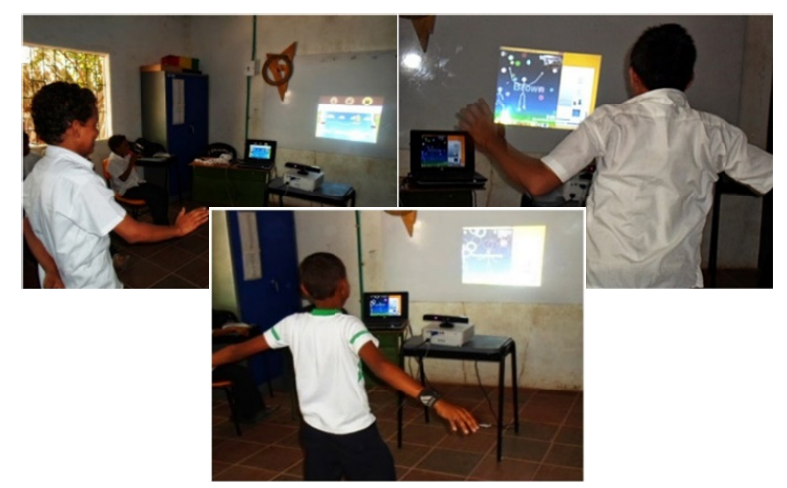

Figure 5. Natural interaction based on MS-Kinect

4) The prototype and its activities

In the main screen of the developed prototype, shown in the Figure 6(a), you can see some buttons that allow access to the proposed play activities, these buttons are activated with the click gesture. In figure 6 (b) the "Sort" activity screen is displayed. Figure 6 (c) shows the start screen of the playful activity "Parear". Figure 6 (d) shows the initial screen of the Sumar play activity. In each of the proposed play activities, 2 buttons are available at the top. The back button allows you to cancel the current game and return to the main screen and, the second button, restart allows you to start the current activity again.

As mentioned in previous sections, the developed prototype has the possibility of being configured in some of its aspects. The options that can be configured are:

- A number of elements that each activity can use.

- Images that are loaded in each game. 
- For the case of the order and pair activities, you can configure the minimum and a maximum number of elements that can be displayed in a game.

The configuration of these options is done by modifying some files that are read when the application is executed. Each activity has its own characteristics, therefore, each one has its own configuration file, and these files are located in the/config/directory, located in the installation folder of the application. The structure of the files is defined in XML. It should be noted that in the case of the Sort activity, the software does not resize the images so that they fit the order of the elements, therefore, they must be created with the size differences that you want to use.

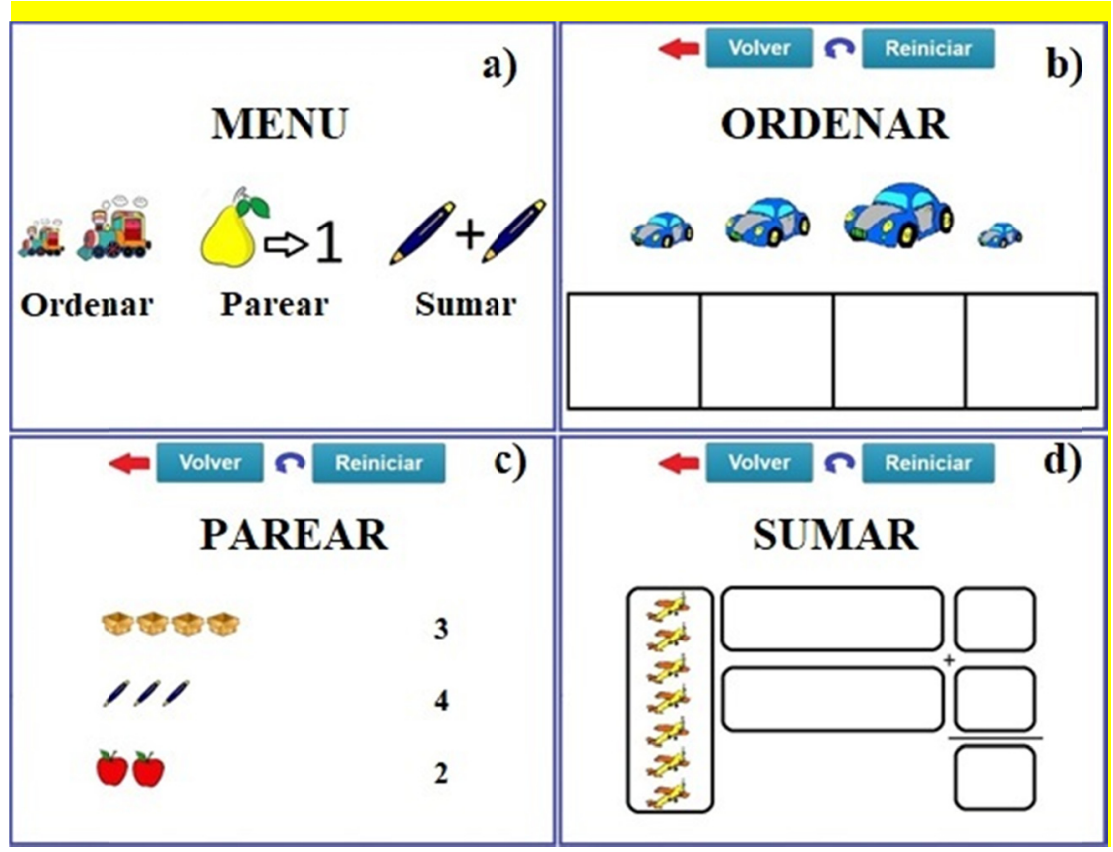

Figure 6. KARMLS screens

\section{5) Evaluation}

To carry out the prototype evaluation, a field test was carried out in two Basic Education Units of the City of Riobamba, Ecuador. The study used the students' t-test for paired samples to check if there is a statistically significant difference between the means of the scores obtained by the children when they learned and practiced the contents in a traditional way (practicing in their textbook) and the scores obtained after using the computer tool KARMLS (based on AR) to practice what was learned. The obtained data also allowed a comparison with the scores obtained by children with low performance (less than 14, on a scale where the maximum score, ie 32 points is equivalent to 20 points) compared to those who present a high performance (14 or more) to compare the level of progress of these two groups of children after using KARMLS. For this, a comparison of the percentage of improvement (Improvement = using KARMLS - traditional way) was realized obtained by each children group, using the average of their qualifications and considering the aforementioned scale. The results of these analyses are presented in the following section.

\section{Results and Discussion}

The experiment produced 58 qualifications ( 29 from pretest and 29 from posttest), being 32 points the maximum score that could be reached. From these scores, the students' $t$-test for paired samples was performed between the obtained qualifications by the children participating in the study before and after using KARMLS. In order to verify the difference existing after using the proposed AR tool, the evaluated variable is the difference between the means of the scores obtained in the posttest minus the scores obtained in the pretest. The results of this test are those shown in Table 3. 
Table 3. Qualifications obtained in pretest/posttest

\begin{tabular}{|c|c|c|c|c|c|}
\hline \multicolumn{6}{|c|}{ Qualifications (Over 32 points) } \\
\hline Subject $\mathrm{N}^{\circ}$ & $\begin{array}{c}\text { Before } \\
\text { KARMLS }\end{array}$ & $\begin{array}{c}\text { After } \\
\text { KARMLS }\end{array}$ & Subject $\mathrm{N}^{\circ}$ & $\begin{array}{c}\text { Before } \\
\text { KARMLS }\end{array}$ & $\begin{array}{c}\text { After } \\
\text { KARMLS }\end{array}$ \\
\hline 1 & 18 & 20 & 16 & 25 & 31 \\
\hline 2 & 18 & 20 & 17 & 26 & 26 \\
\hline 3 & 19 & 22 & 18 & 26 & 29 \\
\hline 4 & 19 & 22 & 19 & 27 & 26 \\
\hline 5 & 20 & 23 & 20 & 27 & 30 \\
\hline 6 & 20 & 23 & 21 & 28 & 28 \\
\hline 7 & 21 & 24 & 22 & 28 & 30 \\
\hline 8 & 21 & 24 & 23 & 29 & 28 \\
\hline 9 & 22 & 24 & 24 & 29 & 29 \\
\hline 10 & 22 & 24 & 25 & 30 & 28 \\
\hline 11 & 23 & 25 & 26 & 30 & 29 \\
\hline 12 & 23 & 25 & 27 & 31 & 28 \\
\hline 13 & 24 & 26 & 28 & 31 & 31 \\
\hline 14 & 24 & 32 & 29 & 32 & 29 \\
\hline \multirow[t]{2}{*}{15} & 25 & 26 & & & \\
\hline & & \multicolumn{2}{|c|}{ Before } & $\begin{array}{c}\text { After } \\
\text { KARMLS }\end{array}$ & Difference \\
\hline \multicolumn{2}{|r|}{ Mean } & \multicolumn{2}{|c|}{24.7586207} & 6.27586207 & 1.5172 \\
\hline \multicolumn{2}{|c|}{ Variance } & \multicolumn{2}{|c|}{18.1896552} & 0.99261084 & 7.197 \\
\hline \multicolumn{2}{|c|}{ Observations } & \multicolumn{2}{|c|}{29} & 29 & \\
\hline \multicolumn{2}{|c|}{ Pearson correlation coefficien } & \multicolumn{2}{|c|}{0.82572505} & & \\
\hline
\end{tabular}

Made by the authors.

Before carrying out the students' $t$-test, the normality test of the samples corresponding to the grade obtained by the children is carried out before and after using KARMLS as a tool to practice the knowledge referring to Sort, Match and Add. To do this, the Excel Realstats complement is used to perform the Shapiro Wilk normality test, the results of this test are shown in Table 4:

Table 4. Shapiro Wilk normality test results

\begin{tabular}{ll}
\hline Before KARMLS (Sample A) & After KARMLS (Sample B) \\
\hline $\mathrm{n}=29$ & $\mathrm{n}=29$ \\
Average $=24.7586$ & Average $=26.2758$ \\
Standard deviation $=4.2649$ & Standard deviation $=3.315510645049782$ \\
$\mathrm{~W}=0.9542$ & $\mathrm{~W}=0.962843254$ \\
Value of the $\mathrm{SW}$ table for $0.95 \%(\mathrm{p}=0.05)=0.9259->$ HO accepted & Value of the $\mathrm{SW}$ table for $0.95 \%(\mathrm{p}=0.05)=0.9259$ - $>$ HO accepted \\
Conclusion: There is no statistical evidence that indicates that the & $\begin{array}{l}\text { Conclusion: There is no statistical evidence that indicates that the data } \\
\text { data obtained in the pretest are not normal. }\end{array}$ \\
\hline
\end{tabular}

Made by the authors.

After having checked the normality of the samples, it was determined that the probability distribution that would be used for the study is the students' t-test for related samples, this test allows to determine if there is a statistically significant difference between the qualifications averages obtained by the children before and after using KARMLS. The results of the students' t-test are shown in Table 5. 
Table 5. Results of students' t-test for the related samples

\begin{tabular}{|c|c|c|c|c|c|}
\hline \multicolumn{2}{|c|}{ SUMMARY } & \multirow{2}{*}{ Mean } & \multirow{2}{*}{$\frac{\text { Alpha }}{\text { Std Dev }}$} & \multirow{2}{*}{$\begin{array}{c}0.05 \\
\mathrm{t}\end{array}$} & \\
\hline Groups & Count & & & & \\
\hline Before & 29 & 24.75862069 & 4.2649 & & \\
\hline After & 29 & 26.27586207 & 3.3155 & & \\
\hline Diff. & 29 & -1.51724137 & 2.4145 & -3.3839 & \\
\hline T-Test & p-value & t-crit & Lower & upper & Sig \\
\hline Two tails & 0.0021291 & 2.048407142 & -2.436 & -0.5987958 & Yes \\
\hline
\end{tabular}

Made by the authors.

From the obtained data for the calculated $t$ value $(t=-3.3839)$ and for $t$ critical to two tails for $n=29$ ( $t$-crit $=$ 2.0484 ) and with the $p$-value for two tails ( $\mathrm{p}$-value $=0.0021291$ ), the null hypothesis is rejected and it is concluded that the difference between the averages obtained before (24.76) and after (26.28) of the use of KARMLS is statistically significant and that the observed improvement is it must to the use of the computer system developed in the present study and that is not a random result.

Next, we present the analysis that allows to compare the level (measured in percentage) of improvement of the group of children considered as poor performers (they obtained less than 14 points in the pretest) with the level of improvement of the group of children of high performance (obtained 14 or more points in the pretest). Table 6 shows the scores obtained by children before and after using KARMLS, separate into two groups (low and high performance). These qualifications are presented on a scale in which the maximum score, that is 32 , equals 20 points. 
Table 6. Separated children in high and low-performance groups

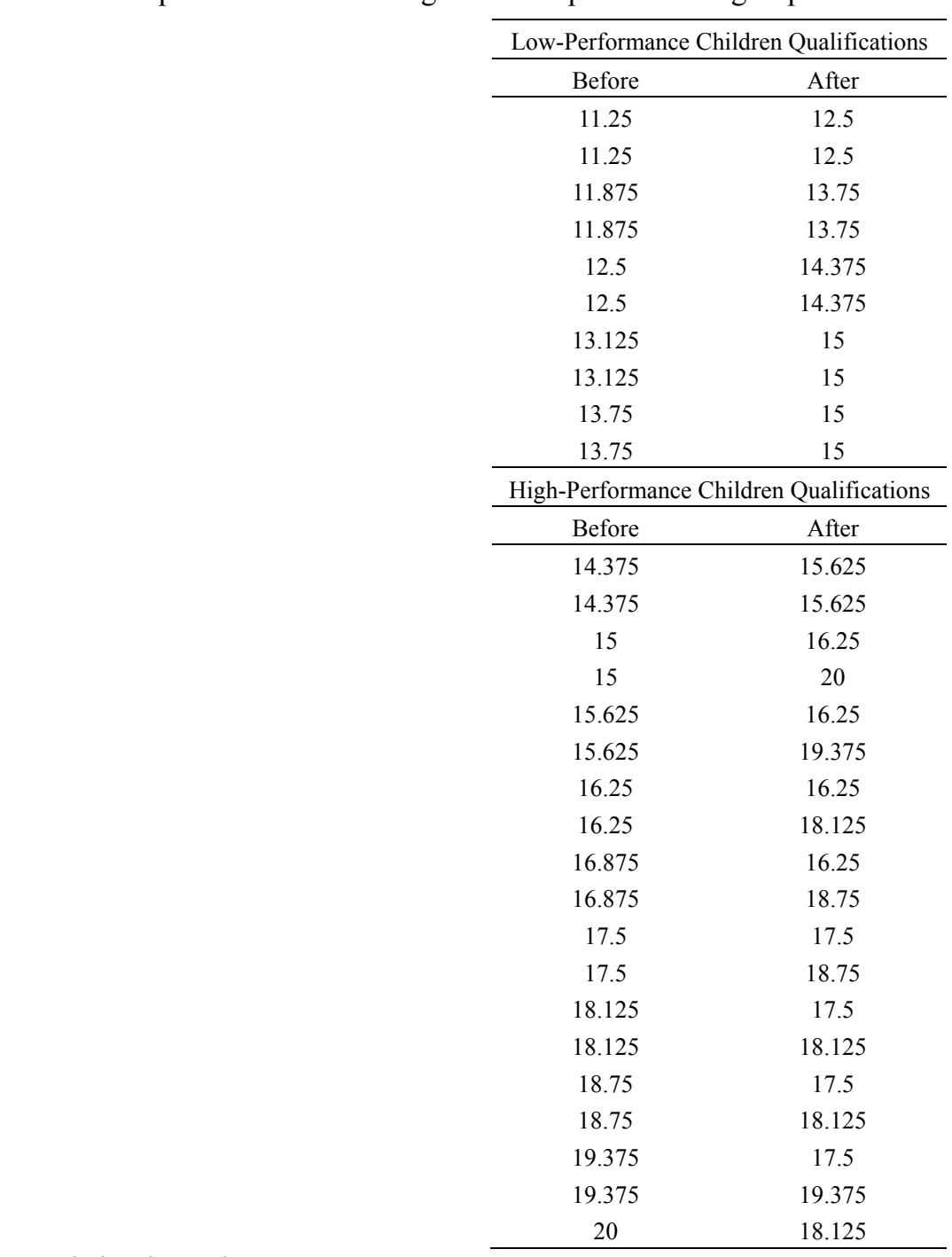

Made by the authors.

The average obtained by children in the low-performance group is 12.5 in the pretest and 14.125 in the posttest, then it is determined that there is an increase of 1.63 points equivalent to $13 \%$ in the average of their grades after using KARMLS with respect to the grades obtained in the pretest. As for the high-performance group, it is observed that the average of their qualifications is 17.04 for the pretest and 17.63 for the posttest, with an increase of 0.59 points after using KARMLS, that is, the average of their grades increased $3.47 \%$ after using KARMLS. It is observed that the computer tool produced more significant gains in learning the group of children with low performance than in the high-performance group.

It was observed that most of the children did not have problems when using the application and did not need help to perform the interaction with the AR software, this fact shows the little extrinsic cognitive load that this form of interaction generates, this allowed the children have a better understanding about each game's objective. However, it was also observed that a small number of children could not understand at first glance the movements that corresponded to the gestures that allow controlling the activities. In these cases, it was necessary to assist the child to complete the proposed activity, which started again when this difficulty was detected. This facts, indicate that the experience was positive and that the prototype implemented fulfills with the proposed objectives.

\section{Conclusions}

The analysis of obtained data in the experiment made it possible to determine that there is a statistically significant improvement between the scores obtained by the children participating in the study in the test that measures their performance after using KARMLS in comparison with their grades obtained before using the proposed system. 
The analysis made it possible to corroborate that there was a greater improvement in the children with low performance in comparison with the children of the high-performance group, it has been considered that the possible reasons for this finding can be: a) many of the scores obtained by the children of the group of high performance are very high, there is even a case in which the maximum possible score was obtained, this makes the space for improving the performance of these children is quite limited and $b$ ) the test was quite basic, so much that children of the high-performance group dominated these topics and it was very easy for them to achieve high scores before and after using KARMLS.

New research should address the usefulness of augmented reality from a psychological perspective since it is necessary to have a theory to describe and predict the learning outcomes in the space where the real and the virtual combine in order to offer beneficial educational experiences, for To achieve this goal, we must first understand the underlying technological and psychological factors on which Augmented Reality is beneficial (or not) in an educational experience, this understanding will allow both curricular designers and teachers and computer professionals to make use of the specific benefits and potentialities of a didactic digital resource based on AR.

During the execution of the present study it was possible to verify what is stated in Hsu (2011), work that affirms that an application based on this type of technology has a high motivational level in students, especially preschool.

MS-Kinect is an interactive device that presents several possibilities in terms of applications for the educational field, the present study has used the depth map, one of the forms of interaction that MS-Kinect supports, this fact makes it possible to improve in certain characteristics As it is the recognition and monitoring of gestures, it is a pending task the analysis of other interaction options that this device can offer.

There is still a gap in terms of interaction standards with technologies without controls. At present, this type of interaction is used mostly in the field of videogames, with little guidance and/or conventions to guide the programmer in the design of this type of interaction.

It highlights the usability of applications based on technologies without controls similar to MS-Kinect, and its support in teaching-learning processes, this being a little explored field, since, in the case of new users, it is essential to analyze the cognitive abilities of these users when taking on the challenge of designing applications in the educational field. This analysis must be carried out with the purpose of not underestimating or overestimating the users in terms of their capabilities.

\section{Future Jobs}

The potential that this type of devices presents for the field of education opens new doors for research and the development of future applications. The development of new educational games based on MS-Kinect that contemplates other themes or other forms of interaction can be investigated.

Heuristics should be developed that help in determining the educational game's usability for children, since they present differences compared with the users for whom the commercial videogames are designed.

\section{References}

Boulos, M. N. K., Blanchard, B. J., Walker, C., Montero, J., Tripathy, A., \& Gutierrez-Osuna, R. (2011). Web GIS in practice X: a Microsoft Kinect natural user interface for Google Earth navigation. International journal of health geographics, 10(1), 45. https://doi.org/10.1186/1476-072X-10-45

Bravo, J. L., Tordesillas, M. J., Padrón, M. A., Jerez, N. A., González, V., \& Blanco, A. (2011). Plataforma Accesible en el Marco de la Rehabilitación Físico-Cognitiva. In Décima Conferencia Iberoamericana en Sistemas, Cibernética e Informática (CISCI 2011). 8th Simposium Iberoamericano en Educación, Cibernética e Informática (Vol. 19).

Bujak, K. R., Radu, I., Catrambone, R., Macintyre, B., Zheng, R., \& Golubski, G. (2013). A psychological perspective on augmented reality in the mathematics classroom. Computers \& Education, 68, 536-544. https://doi.org/10.1016/j.compedu.2013.02.017

Carter, M., Velloso, E., Downs, J., Sellen, A., O’Hara, K., \& Vetere, F. (2016). PathSync: multi-user gestural interaction with touchless rhythmic path mimicry. In Proceedings of the 2016 CHI Conference on Human Factors in Computing Systems (pp. 3415-3427), ACM. https://doi.org/10.1145/2858036.2858284

Chong, T. S. (2005). Recent Advances in Cognitive Load Theory Research: Implications for Instructional Designers. Malaysian Online Journal of Instructional Technology (MOJIT), 2(3), 106-117.

Cohen, R., \& Swerdlik, M. (2001). Pruebas y Evaluación Psicológica. Introducción a las pruebas y a la Medición. Mexico: Mc Graw Hill. 
Cordova, D. I., \& Lepper, M. R. (1996). Intrinsic motivation and the process of learning: Beneficial effects of contextualization, personalization, and choice. Journal of educational psychology, 88(4), 715. https://doi.org/10.1037/0022-0663.88.4.715

Cui, Y., \& Stricker, D. (2011). 3d shape scanning with a kinect. In ACM SIGGRAPH 2011 Posters (p. 57). ACM. https://doi.org/10.1145/2037715.2037780

DePriest, D., \& Barilovits, K. (2011). LIVE: Xbox KinectC s virtual realities to learning games. In TCC (pp. 48-54). TCCHawaii.

Ellis, J., Fosdick, B. K., \& Rasmussen, C. (2016). Women 1.5 times more likely to leave STEM pipeline after calculus compared to men: Lack of mathematical confidence a potential culprit. PloS one, 11(7), e0157447. https://doi.org/10.1371/journal.pone.0157447

Gallo, L., Placitelli, A. P., \& Ciampi, M. (2011, June). Controller-free exploration of medical image data: Experiencing the Kinect. In 2011 24th international symposium on computer-based medical systems (CBMS) (pp. 1-6). IEEE. https://doi.org/10.1109/CBMS.2011.5999138

Gossen, T., Nitsche, M., \& Nürnberger, A. (2013). Evolving Search User Interfaces. In EuroHCIR (pp. 31-34).

Hsu, H. M. J. (2011). The potential of Kinect as interactive educational technology. In 2nd International Conference on Education and Management Technology, Singapur. https://doi.org/10.7763/IJIET.2011.V1.59

Huang, J. D. (2011, October). Kinerehab: A Kinect-based system for physical rehabilitation: A pilot study for young adults with motor disabilities. In The proceedings of the 13th international ACM SIGACCESS conference on Computers and accessibility (pp. 319-320). ACM. https://doi.org/10.1145/2049536.2049627

Izadi, S., Kim, D., Hilliges, O., Molyneaux, D., Newcombe, R., Kohli, P., ... \& Fitzgibbon, A. (2011, October). Kinect Fusion: real-time 3D reconstruction and interaction using a moving depth camera. In Proceedings of the 24th annual ACM symposium on User interface software and technology (pp. 559-568). https://doi.org/10.1145/2047196.2047270

Johnson, L., Adams, S., \& Cummins, M. (2012). NMC Horizon Report: 2012 K-12 Edition (Austin, TX: New Media Consortium, 2012).

Kandroudi, M., \& Bratitsis, T. (2012). Exploring the educational perspectives of XBOX Kinect based video games. In Proceedings of ECGBL 2012 (pp. 219-227).

Kaufmann, H. (2002, December). Construct3D: an augmented reality application for mathematics and geometry education. In Proceedings of the tenth ACM international conference on Multimedia (pp. 656-657). ACM. https://doi.org/10.1145/641007.641140

Khaleel, Y. F. (2019). Assessing the Knowledge Level of Teachers of Children with Autism Spectrum Disorder about the Importance of Applied Behavior Analysis (ABA) Strategies in Zarka City. International Education Studies, 12(5). https://doi.org/10.5539/ies.v12n5p120

Khan, M., Trujano, F., Choudhury, A., \& Maes, P. (2018, April). Mathland: Playful Mathematical Learning in Mixed Reality. In Extended Abstracts of the 2018 CHI Conference on Human Factors in Computing Systems (p. D108). https://doi.org/10.1145/3170427.3186499

Khoshelham, K., \& Elberink, S. O. (2012). Accuracy and resolution of Kinect depth data for indoor mapping applications. Sensors, 12(2), 1437-1454. https://doi.org/10.3390/s120201437

Kitsunezaki, N., Adachi, E., Masuda, T., \& Mizusawa, J. I. (2013, May). KINECT applications for physical rehabilitation. In Medical Measurements and Applications Proceedings (MeMeA), 2013 IEEE International Symposium on (pp. 294-299). IEEE. https://doi.org/10.1109/MeMeA.2013.6549755

Lee, J. C. (2008). Hacking the nintendo wii remote. IEEE pervasive computing, 7(3), 39-45. https://doi.org/10.1109/MPRV.2008.53

Lotero, L. A. A. (2012). Teoría de la carga cognitiva, diseño multimedia y aprendizaje: un estado del arte. Magis: Revista Internacional de Investigación en Educación, 5(10), 75-92.

Lozada, R., Rivera, L., \& Molina, F. (2018). MS-Kinect in the development of educational games for preschoolers. International Journal of Learning Technology, 13(4), 277-305. https://doi.org/10.1504/IJLT.2018.098500

Molina-Granja, F., \& Rodríguez-Rafael, G. D. (2017a). Model for digital evidence preservation in criminal 
research institutions-PREDECI. International Journal of Electronic Security and Digital Forensics, 9(2), 150-166. https://doi.org/10.1504/IJESDF.2017.10004412

Molina-Granja, F., \& Rodríguez-Rafael, G. D. (2017b). The preservation of digital evidence and its admissibility in the court. Int. J. Electronic Security and Digital Forensics, 9(1), 1-18. https://doi.org/10.1504/JJESDF.2017.10002624

Neifeald, E., \& Nissim, Y. (2019). Co-Teaching in the "Academia Class": Evaluation of Advantages and Frequency of Practices. International Education Studies, 12(5), 86-98. https://doi.org/10.5539/ies.v12n5p86

Ortega, J. J., \& Obispo, J. A. (2007). Manual de psicomotricidad (Teoria, exploración, programación y practica). Ediciones La Tierra Hoy SL.

Papert, S. (1999). Logo philosophy and implementation. Logo Computer Systems Inc.

Perkins, D. (1999). The many faces of constructivism. Educational leadership: journal of the Department of Supervision, 57(3), 6-11.

Romero-Molano, C. A., \& Díaz-Celis, C. A. (2011, October). Navegación de robot móvil usando Kinect y OpenCV. In Congreso Internacional de Ingeniería Mecatrónica-UNAB (Vol. 2, No. 1).

Sampieri, R., Fernández, C. \& Baptista, P. (2014). Metodoogía de la Investigación (6th ed.). México D.F., México: McGRAW-HILL/INTERAMERICANA EDITORES, S.A. DE C.V.

Stowers, J., Hayes, M. P., \& Bainbridge-Smith, A. (2011, June). Quadrotor Helicopter Flight Control Using Hough Transform and Depth Map from a Microsoft Kinect Sensor. In MVA (pp. 352-356).

Sweller, J. (1994). Cognitive Load Theory, Learning Difficulty, and Instructional Design. Learning and Instruction, 4(4), 295-312. https://doi.org/10.1016/0959-4752(94)90003-5

Sweller, J. (2010). Element interactivity and intrinsic, extraneous, and germane cognitive load. Educational Psychology Review, 22(1), 123-138. https://doi.org/10.1007/s10648-010-9128-5

Sweller, J., Van Merrienboer, J., \& Pass, F. (1998). Cognitive architecture and instructional design. Educational Psychology Review, 10(5), 251-296. https://doi.org/10.1023/A:1022193728205

Wei, X., Guo, D., \& Weng, D. (2018). Improving Authentic Learning by AR-Based Simulator. In Chinese Conference on Image and Graphics Technologies (pp. 124-134). Springer, Singapore. https://doi.org/10.1007/978-981-13-1702-6_13

\section{Copyrights}

Copyright for this article is retained by the author(s), with first publication rights granted to the journal.

This is an open-access article distributed under the terms and conditions of the Creative Commons Attribution license (http://creativecommons.org/licenses/by/4.0/). 